DOI: https://doi.org/10.24867/13AM07Vujanovic

\title{
PROJEKTOVANJE PROTIVPRITISNE PARNE TURBINE ZA POTREBE KOGENERACIJE
}

\section{DESIGN OF BACK-PRESSURE STEAM TURBINE FOR COGENERATION}

\author{
Stefan Vujanović, Borivoj Stepanov, Fakultet tehničkih nauka, Novi Sad
}

\begin{abstract}
Oblast- TOPLOTNE TURBOMAŠINE
Kratak sadržaj - Cilj rada jeste projektovanje protivpritisne turbine, koja podmiruje potrebe za toplotom i strujom, i funkcioniše kogenerativno. Kogeneraciona postrojenja imaju veliku prednost u odnosu na konvencionalna, iz razloga što se njihovom upotrebom štedi primarni izvor energije, smanjuje se uticaj na globalno zagrevanje, $i$ raste efikasnost celokupnog sistema. Primenom kogeneracije, efikasnost postrojenja raste i do 40\%, u zavisnosti od toga kakav se sistem koristio pre primene iste. U radu je detaljno prikazan termodinamički proračun sa ciljem dimenzionisanja turbine, i njenih delova.
\end{abstract}

Ključne reči: Protivpritisna turbina, parna turbina, kogeneracija, energetska efikasnost

Abstract - The aim of this work is to design a backpressure turbine, which will deliver heat and power in the cogeneration sense. Cogeneration plants have a great advantage over conventional ones, because their use saves the primary energy source, reduces the impact on global warming, and increases the efficiency of the entire system. By applying cogeneration, the efficiency of the plant increases up to $50 \%$, depending on what kind of system was used before its application. In this paper thermodynamic calculations for sizing the turbine and its parts are presented in detail.

Keywords: Back-pressure turbine, steam turbine, coogeneration, energy efficiency

\section{UVOD}

Kogeneracija ili skraćeno CHP, predstavlja spregnutu proizvodnju toplotne i električne energije. Ovde se otpadna toplota iz procesa, koristi za generisanje električne energije, koja se može poslati u gradsku mrežu, po potrebi. Postoji mogućnost stvaranja i energije za hlađenje, takođe od otpadne toplote - trigeneracija (CCHP). Korišćenjem CHP-a, efikasnost celokupnog postrojenja raste za 30$40 \%$, dok se troškovi goriva smanuju za $50 \%$.

Ono što je bitno napomenuti, jeste da prelazak na kogeneraciju, $u$ određenom broju slučajeva uslovljava i prelazak sa korišćenja uglja kao primarnog izvora energije, na gas, što direktno utiče na smanjenje emisionih gasova [1].

Turbine su mašine koje pretvaraju toplotnu energiju $u$ kinetičku, a potom nju u mehanički rad u obliku obrtanja rotora.

\section{NAPOMENA:}

Ovaj rad proistekao je iz master rada čiji mentor je dr Borivoj Stepanov.
Radna mašina koju turbina pokreće, može biti generator $u$ kojem se mehanički rad pretvara u električnu energiju. Dva funkcionalna elementa svake turbine su nepokretno pretkolo sa sprovodnim lopaticama poređanim po njegovom obimu (stator), i radno kolo sa radnim lopaticama, takođe poređanim po njegovom obimu (rotor). Radno kolo mora biti pričvršćeno za osovinu, kojom se obrtni moment prenosi na radnu mašinu. Proces prenošenja kinetičke energije fluidne struje na rotor se postiže se definisanim oblikom lopatica.

Osovina pokreće generator, u kom se stvara električna energija, a para niskog pritiska koja izlazi iz turbine se koristi za druge potrebne procese.

Pri upotrebi CHP tehnologije, najviše se koriste protivpritisne turbine, kod kojih se para visokog pritiska konvertuje u električnu energiju, dok se para niskog pritiska koristi za razne procese u fabrici. Efikasnost turbine zavisi od ulaznih parametara (koji treba da budu što je moguće viši), i od izlaznih parametara (koji treba da budu što manji). Razlika između ova dva parametra diktira efikasnost turbine. Efikasnost ovih turbina je uglavnom manja od ostalih, iz razloga što se većina energije pare, kao i latentna toplota isparavanja koriste $\mathrm{u}$ celokupnom procesu, a ne u radu turbine. Ali iz tog razloga, stepen efikasnosti celog procesa je veći, nego kad se koriste ostali tipovi turbina.

Jedna od glavnih odlika ovih tipova turbine, jeste odsustvo kondenzatora. Na kraju procesa se para ne pretvara u kondenz, i vraća u ciklus, već se, kao što je gore navedeno, koristi za druge procese. Koriste se u naftnim rafinerijama, industriji hrane, šećera, tj. $\mathrm{u}$ industriji gde su potrebne velike količine procesne pare $[1,6]$.

\section{PRORAČUN POTREBNE KOLIČINE PARE}

Prva prepreka koju treba premostiti, jeste određivanje količine pare koju generator treba da proizvede, da bi turbina mogla da radi u zadatim parametrima.

Da bi se povećao stepen efikasnosti celokupnog procesa parne turbine, potrebno je povećati temperature napojne vode, pre ulaska u generator pare. Samim tim je generator rasterećeniji, jer troši manje energije za zagrevanje radnog fluida na potrebnu temperature.

Ovo se postiže oduzimanjem toplote pare nakon nekog stupnja. Ovaj proces se odigrava preko razmenjivača toplote.

Zadati parametri:

$P_{\mathrm{EL}}=8000 \mathrm{~kW}$ - snaga koju mora proizvesti električni generator

$p_{\mathrm{OD}}=16$ bar - pritisak oduzimanja pare

$p_{\mathrm{p}}=6 \mathrm{bar}-$ pritisak pri kom ekspandira ostatak pare 
$\eta_{m}=0.96-$ stepen iskorišćenja usled mehaničkih gubitaka

$\eta_{\mathrm{EL}}=0.95-$ stepen iskorišćenja usled gubitaka $\mathrm{u}$ generatoru električne energije

Stanje pregrejane pare pre prigušenja:

$p_{0}=70$ bar

$t_{0}=500 \mathrm{bar}$

$h_{0}=3411 \frac{\mathrm{kJ}}{\mathrm{kg}}$

Stanje pregrejane pare nakon prigušenja od 5\%:

$p_{1}=0,95 \cdot p_{0}=0,95 \cdot 70=66,5 \mathrm{bar}$

$t_{0}=500$ bar

$h_{0}=3415 \frac{\mathrm{kJ}}{\mathrm{kg}}$

Primer šeme kogenerativnog sistema dizajniranog $u$ AutoCAD 2021, koji koristi protivpritisnu turbinu dat je na slici 6.

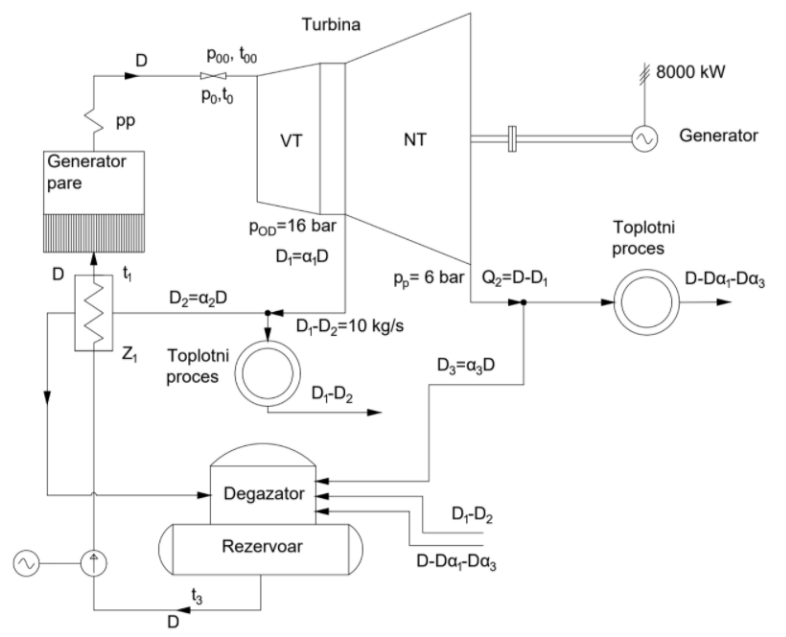

Slika 1. Šema kogenerativnog sistema

\section{TERMODINAMIČKI PRORAČUN TURBINE}

U daljem radu biće dat primer proračuna jednog stupnja protivpritisne parne turbine. Kod ovih tipova turbine (reakcionih), uvek se ugrađuje jedan akcioni stupanj (Curtisov stupanj), u cilju sprečavanja curenja između statora i rotora.

\subsection{Termodinamički proračun regulacionog kola}

Srednji prečnik radnog kola se uzima na osnovu sledeće formule:

$$
d=\frac{\sqrt{2 H_{0}}}{\pi n} \cdot \frac{u}{c_{\phi}}
$$

Prečnik je ograničen i sa obimnom brzinom radnih lopatica, odnosno centrifugalnom silom $P_{e f} \approx u^{2} / R$.

Razlog tog ograničavanja je čvrstoća savremenih konstrukcionih materijala, koja bi mogla izdržati tako velika toplotna i mehanička naprezanja [2].

Zbog toga se turbinska postrojenja grade sa većim brojem stupnjeva, uz postepenu ekspanziju pare, pri čemu obimna brzina lopatica u kondenzacionim parnim turbinama sa više stupnjeva iznosi $120-150 \mathrm{~m} / \mathrm{s}$, za stupnjeve srednjeg i visokog pritiska, odnosno $350-450 \mathrm{~m} / \mathrm{s}$ za stupnjeve nižih pritisaka.

U osnovi valja imati u vidu da se zbog pomenutih ograničenja obimna brzina uzima manja od $600 \mathrm{~m} / \mathrm{s}$, a najčešće do $400 \mathrm{~m} / \mathrm{s}$. Pri tome je u većini slučajeva Mahov broj manji od 1.Odabrana vrednost je $600 \mathrm{~mm}$ [2].
Smanivanje obimne brzine na periferiji lopatica smanjuje eroziju lopatica, jer se smanuje i centrifugalna sila koja deluje na makrokapljice vlage. Kod projektovanja turbine treba izabrati optimalan odnos $\mathrm{U} / \mathrm{C}_{\mathrm{F}}$ (slobodne i fiktivne brzine). Naravno, smanjivanje dužine lopatica poslednjih stupnjeva, utiče na porast izlaznih gubitaka i pogoršava ekonomičnost turbine. Smanjivanje broja lopatica sprovodnog aparata utiče na umanjenje uticaja vlage, jer se time smanuje količina krupno-disperzne vlage, koja se sliva, i zatim pada na lopatice $[2,3]$.

Pasivne metode borbe sa erozijom lopatica obuhvataju:

- $\quad$ primena eroziono otpornih materijala za izradu lopatica

- primena delimičnih obloga lopatica sa eroziono otpornim materijalima

- termička i elektrolučna obrada lopatica ili jednog njihovog dela, kao i nanošenje eroziono otpornih slojeva

Reaktivnost predstavlja odnos između raspoloživog toplotnog pada rotorskih lopatica i zbira raspoloživih toplotnih padova statorskih i rotorskih lopatica.

Kada je reaktivnost veća od 0 , strujanje se u rotorskim lopaticama ubrzava. Ukoliko je u stupnju $\mathrm{R}_{\mathrm{sr}}=0$, $\mathrm{u}$ pitanu je akcioni stupanj (ne koriste se u praksi), dok vrednosti veće od 0,4 važe za reakcione stupnjeve. Kod reakcionih turbina sa više stupnjeva, uzima se vrednost $R_{s r}=0,5 \mathrm{kao}$ u ovom slučaju. Proces ekspanzije pare povezan je sa pretvaranjem potencijalne energije u kinetičku: entalpija pare se smanjuje, a raste brzina isticanja. $U$ inženjerskim proračunima parne turbine, pogodno je proces ekspanzije pare prikazati u i-s dijagramima. Stanje pare pred mlaznicama odgovara zadatim parametrima pare. Pri proračunu stupnja, obično se zadaje pritisak $p_{o} i$ temperatura $t_{0}$ pred mlaznicama, pritisak na izlazu mlaznica $\mathrm{p}_{1}$ i brzina pare na ulazu u kanal mlaznica, $\mathrm{c}_{\mathrm{o}}$.

Posmatrajući isticanje pare iz mlaznice $u$ idealnom slučaju, pretpostavlja se da se proces odvija bez razmene toplote sa okolinom, bez gubitaka trenja, i usled turbulentnog stujanja [2,3].
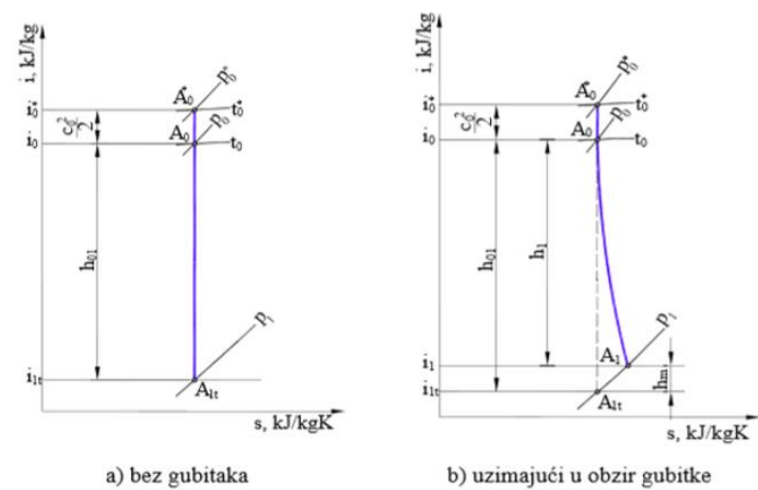

b) uzimajući u obzir gubitke

\section{Slika 2. Proces ekspanzije u mlaznicama [2]}

U turbine se sveža para dovodi iz parnog kotla parovodima, a u mlaznice (Slika 2., pozicija 1), ulazi sa pritiskom $p_{o} i$ brzinom $c_{o}$. U mlaznicama se vrši ekspanzija (prigušivanje) pare od pritiska $p_{o}$ na pritisak $p_{1}$, pri čemu se brzina pare povećava na $p_{1}$. Pošto je izvršena ekspanzija pare do izlaznog pritiska iz stupnja $\mathrm{p}_{2} \approx \mathrm{p}_{1}$, 
izvršena je i potpuna transformacija potencijalne energije pare u kinetičku energiju.

Sada iz mlaznica ističe para apsolutnom brzinom $\mathrm{c}_{1}, \mathrm{a} u$ međulopatični kanal radnih lopatica (2) ulazi relativnom brzinom $\mathrm{w}_{1}$ pošto su $\mathrm{i}$ ove lopatice $\mathrm{u}$ stanju kretanja obimnom brzinom $u$, na srednjem prečniku $D_{s r}$. Iz mlaznice para ističe pod uglom $\alpha_{1}$, a ulazi $\mathrm{u}$ kanale rotorskih lopatica pod uglom $\beta_{1}$. Para izlazi iz međulopatičnih kanala radnih lopatica apsolutnom brzinom $c_{2}<<c_{1}$ pod uglom $\alpha_{2}$, odnosno relativnom brzinom $w_{2}$ pod uglom $\beta_{2}$. Kao što se vidi iz kinematike strujanja u protočnom delu akcionog stepena dolazi do skretanja struje pare u međulopatičnim kanalima radnih lopatica. Zbog toga se pojavljuju sile centrifugalnog pritiska na lopatice koje i vrše koristan rad, što u stvari predstavlja akciono dejstvo pare. Interesantne su komponente brzine $\mathrm{u}$ smeru obimne brzine, kao i komponenta akcione sile u tom smeru. Delovanjem sile na lopatice, upravo na sredni prečnik rotora, obrazuje se obrtni moment, usled čega rotor dobija obrtno kretanje. Pošto je kod akcionog stupnja pritisak pare ispod i iza lopatice rotora jednak, izostaje delovanje sile $u$ aksijalnom pravcu, što olakšava rešavanje pitanja ležajeva turbine $[2,3]$.

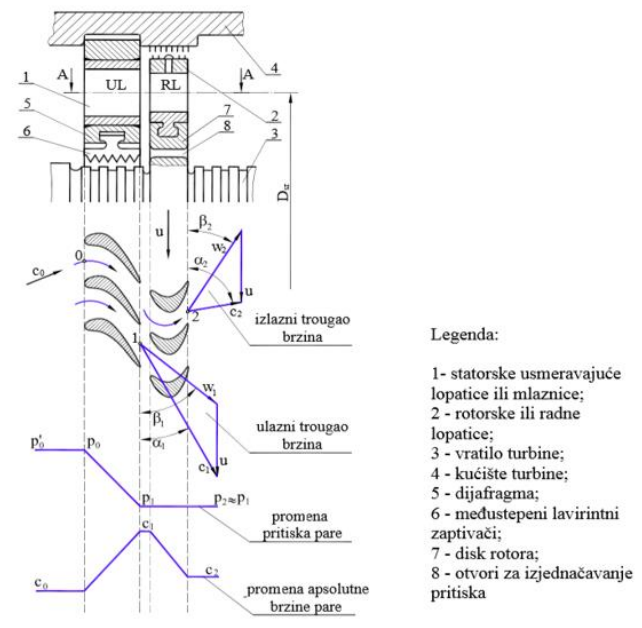

Slika 3. Reakciona turbina [2]

Dovođenje pare u mlaznice turbine može biti realizovano kao parcijalno i potpuno punjenje. Parcijalno punjenje se vrši kada su mlaznice postavljene samo na delu kružnog oboda, tako da para ne ulazi odmah u sve međulopatične kanale radnih lopatica (Slika 3.). Potpuno punjenje se ostvaruje kada su mlaznice postavljene po celom krugu i para se istovremeno uvodi u sve radne lopatice.

Stepen parcijalnosti ili punjenja predstavlja odnos dužine luka $\mathrm{L}_{1}$, koga zauzimaju mlaznice, prema ukupnom obimu kruga $\mathrm{D}_{1} \cdot \pi[2,3]$.

Označava se sa $e$ :

$$
e=\frac{L_{1}}{\pi \cdot D_{1}}
$$

$D_{1}$ - srednji prečnik stepena;

$t_{l}$ - korak rešetke mlaznice na srednjem prečniku $D_{l}$;

$z_{1}-$ broj mlaznica;

$\gamma$ - ugao luka po kome su raspoređene mlaznice.

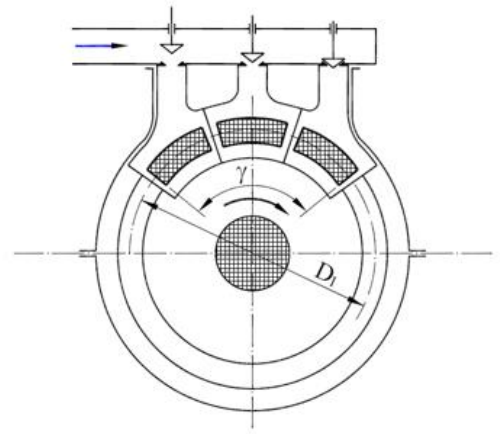

Slika 4. Presek mlaznica [2]

Odabrani profil mlaznica na osnovu $\mathrm{M}_{1 \mathrm{t}}, \alpha_{1 \mathrm{E}}$ iz kataloga lopatica je S-90-12 A (slika 4.).

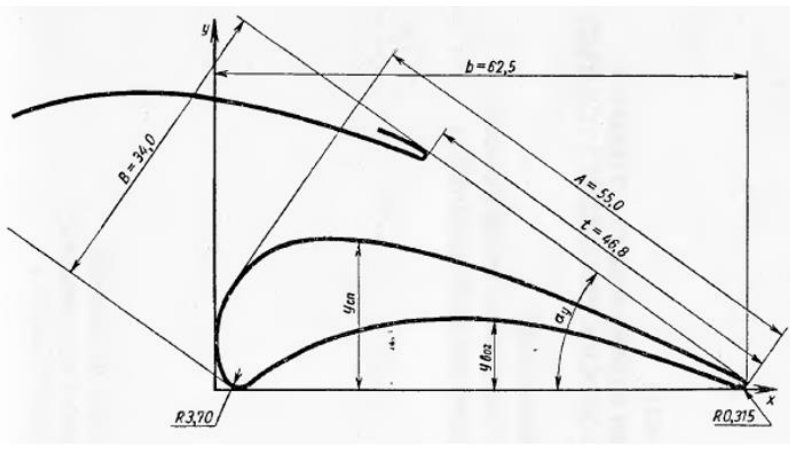

Slika 5. Odabrani profil mlaznica [4]

Odabrani ugao ugradnje profila lopatica je $\alpha_{u}=34^{\circ}$ [4]

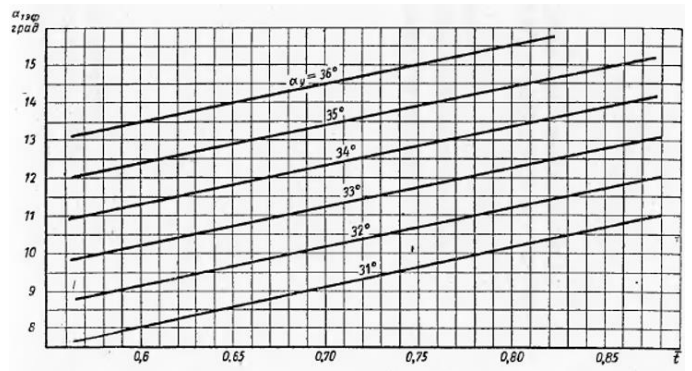

Slika 6. Odabrani ugao ugradnje [4]

Izračunati broj mlaznica:

$$
Z_{1}=\frac{\pi \cdot d_{s r} \cdot e_{1}}{t_{1 o p t}}
$$

Usvojeno $\mathrm{Z}_{1}=25$.

Svi gubici koji se javljaju u turbinama, mogu se razvrstati u dve grupe:

- unutrašnji gubici, koji neposredno utiču na promenu stanja radnog fluida, tačnije pri njegovoj ekspanziji u turbine. $U$ te gubitke spadaju: gubici u mlaznicama, kanalima radnih lopatica, sa izlaznom brzinom pare, zatim gubici u zapornim i regulacionim ventilima, gubici na trenje ...

- $\quad$ spoljašnji gubici, koji ne utiču na promen stanja fluida. U te gubitke spadaju: mehanički gubici i gubici usled proticanja pare kroz zaptivače. 
Zbog rotacije diska, javlja se "mrtva" para, koju je potrebno "pokrenuti" centrifugalnom silom, koja struji od korena prema vrhu lopatica. Rad koji se na ovo troši, umanjuje korisnu energiju turbinskog stupnja.

Gubitak usled trenja se javlja u graničnim slojevima na konkavnoj i konveksnoj strani lopatice, i dovodi do gubitka energije usled zaustavljanja toka u graničnom sloju te površine. Zavisi od debljine graničnog sloja [5]. Stepen efikasnosti regulacionog kola:

$$
\eta_{i}=\eta_{u}-\xi_{y}-\xi_{p a r c}-\xi_{t r}
$$

Ukupan stepen efikasnosti turbine:

$$
\eta_{i}=\frac{h_{0}-h_{3 s t v, N T 4}}{h_{0}-h_{3, I S}}
$$

\section{ZAKLJUČAK}

U ovom radu, urađen je termodinamički, aerodinamički proračun, kao i proračun geometrijskih veličina poput visina lopatica, trougao brzina, itd. za parnu turbinu snage $8000 \mathrm{~kW}$.

Turbina se koristi u kogeneracionom postrojenju, gde protivpritisna turbina ima visok stepen iskorišćenja, jer nema gubitaka toplote ka okolini, već se ona koristi u procesu. Skoro sva toplotna energija pare, biva pretvorena u mehanički rad.

$\mathrm{U}$ radu je dat istorijski prikaz turbina, proračun potrebne količine pare, značaj predgrevanja, dok je većina rada posvećena proračunu stupnjeva turbine, kao i karakteristike istih.

Upotreba kogeneracije i protivpritisne turbine, je sa ekonomske i energetske tačke gledišta jedno od najboljih rešenja što se industrije tiče. Brojke dobijene u ovom radu to i dokazuju.

Električna snaga dobijena za turbinu (umanjena za gubitke u procesu), iznosi $9093 \mathrm{~kW}$.

\section{LITERATURA}

[1] D. F. International, Cogeneration \& Trigeneration How to Produce Energy Efficiently, Berlin: Deutsche Gesellschaft fur Internationale Zusammenarbeit (GIZ) $\mathrm{GmbH}, 2016$.

[2] Z. Milovanović, Energetske mašine, Univerzitet Banja Luka, 2010.

[3] Shhegljaev. A.V., Parovye turbiny, Kyiv Polytechnic Institute, 1993.

[4] Dejch M.E., Atlas profilej reshetok osevyh turbin, St. Petersburg Polytechnic University, 1965.

[5] C. Soares, Gas Turbines, Butterworth-Heinemann, 2014.

[6] ASHRAE, "Combined Heat and Power design guide", Atlanta 2015.

\section{Kratka biografija:}

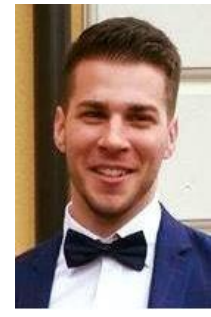

Stefan Vujanović rođen je u Šapcu 1993. godine. Završio je Šabačku gimnaziju 2013. godine. Nakon toga, upisao je osnovne akademske studije na Fakultetu tehničkih nauka iz oblasti Mašinstva - Energetika i procesna tehnika. Odbranio diplomski rad na temu Separacija kapi sredstava za hlađenje i podmazivanje iz otpadnog industrijskog vazduha u oktobru 2018.

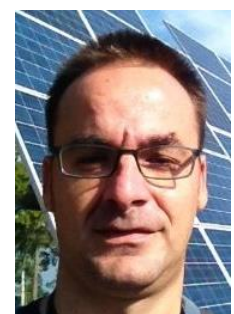

Borivoj Stepanov rođen je u Novom Sadu 1976 godine. Doktorirao na Fakultetu tehničkih nauka 2014 godine, a od 2003 godine predaje predmete koji se bave termoenergetskim postrojenjima. 